\title{
An Awakening (Part II): How You Can Help Science Education
}

BY ROBERT J. FELLER, CHRISTINE R. LOTTER, AND JONATHAN E. SINGER

Science and Education: two academic cultures with a wall between them. How can scientists surmount their own narrow disciplinary interests and capture some of the other culture's excitement? In a previous article (Feller, 2008), the first author, a benthic food-web ecologist, related his personal transitional odyssey from the realm of field and laboratory research to the realm of science education. As Spector and Leard (2008) document so eloquently, these really are two distinctly different cultures.

Many of the problems faced by science teachers at the elementary, middle, and high school levels were listed in Feller (2008), primarily in hopes of increasing awareness on the part of scientists about some of the reasons why undergraduate science majors are not well prepared to embark on their studies.

Robert J. Feller (feller@biol.sc.edu) is Professor, Marine and Biological Sciences, and Director, Center for Science Education, University of South Carolina, Columbia, SC, 29208, USA. Christine R. Lotter is Assistant Professor, Secondary Science Education, University of South Carolina, Columbia, SC, USA. Jonathan E. Singer is Associate Professor, Science Education, University of Maryland, Baltimore County, Baltimore, MD, 21250 USA.
Their problems-both teachers' and students'-are our problems. Make no mistake about it. This is not the time to say "somebody else" should do something about this state of affairs. It is time for all of us to get more involved in STEM (Science, Technology, Engineering, and Mathematics) education.

If we expect undergraduates to have successful journeys through their disciplinary science majors, then we have an obligation to make sure they are properly prepared for undergraduate-level coursework. We are tired of complaining about the very apparent lack of preparedness for understanding science exhibited by today's undergraduates, and we make no distinction between science majors and nonscience majors. Science literacy (knowing a lot about science) is being taught at the expense of scientific literacy (sensu OECD, 2006; i.e., being able to identify scientific issues, to explain phenomena scientifically, and to use scientific evidence). Are your students scientifically literate? Why not? It is time we examine our instructional methods and learn new strategies about how to reform the ways we have been teaching science.

RJF recently asked students in his senior seminar capstone course for undergraduate marine science majors at the University of South Carolina to "think/pair/share" (a pedagogical strategy he learned from his colleagues in the College of Education) with the person sitting next to them about whether anything they did today violated the second law of thermodynamics. Thankfully, after considerable in-class discussion amongst themselves and between student groups, they all agreed that everything they (and ALL organisms, for that matter) do is embedded in this energetic construct. Interestingly, however, many of them still found it difficult to describe what the second law explicitly addresses, but they all understood the concept of energy use and its subsequent degradation. So it is with science. We are hard pressed to think of ANYTHING we do that doesn't have either its structure or function based in science. Even though many of us may have conceptual difficulty with topics like special relativity and quantum physics, we can still appreciate their relevance to our existence. We must make students aware of this dynamic connection between daily life and science, just as we strive to imbue them with an understanding of how the ocean influences their daily lives (e.g., Chen, 2008).

So, what can WE do to combat this deficit in students' preparedness? Even though you are probably telling yourself that if I address this issue it might not 
help me get tenure, there are other tangible benefits that can accrue even if you don't jump completely on the bandwagon of science education. Through your association with science educators you can learn new and better ways to teach. For instance, RJF now uses more inquiry and much less pure lecture in his classes. He now interacts more with students and tries to understand the depth of their knowledge and to identify misconceptions they may have about a given topic BEFORE introducing the topic. As noted in Feller (2007), using a student response (clicker) system is quite effective for ferreting out misconceptions, especially in large classes. Another powerful pedagogical strategy learned through association with science educators is called Phenomenon First. For example, instead of saving that "golly gee whiz holy smoke" image to show at the end of your PowerPoint slideshow, show it first-right up front. Your students will immediately say “wow," even if they don't understand everything about that picture of shark bites on a leg or whatever you have in there for that wow factor. Once engaged or hooked by the "wow" slide, they will ask many more questions than if you simply start talking about shark bite injuries for 10 minutes before showing them what one looks like. Short demonstrations or activities that engage students in problem solving also qualify as "phenomena" and can get students connected and thinking about science as soon as your class begins. They get really excited if you blow something up at the start of class-chemists are particularly good at this use of phenomenon first.

Besides getting help with your own teaching style, many of the following suggestions are consistent with The

Oceanography Society's guide for education and public outreach (Franks et al., 2006), but extend beyond what that innovative publication promotes. The suggestions listed below offer ways that you, the scientist, can make a difference in improving young students' conceptions about how science works and the role that science plays in their lives. More importantly, our list illustrates possible ways that science teachers, science educators, and professional scientists can learn from each other.

\section{IDEAS FOR COLLABORATING WITH SCIENCE EDUCATORS}

\section{AND TEACHERS}

1. Invite a science teacher to participate in your research-you will need to be accommodating, as late afternoons and weekends are the times most teachers would have available for this during the school year. Ask them to bring one or two of their students along. Getting students into a laboratory is known to promote their willingness to choose science as a career path (e.g., Gallagher, 2007). Note: Many teachers will work

\section{So, what can WE do to combat this deficit in students' preparedness?}

in a laboratory during the summer, but please remember, they need to be paid. Teachers often work in teaching-related jobs during the summer just to make ends meet. Most of them probably cannot afford to gain research experience without being paid for their time and effort. You ask, "How much?" Somewhere between $\$ 3500-\$ 5000$ for the summer should do it. You will learn a lot about what teachers need for their classrooms during this summer experience. Similar to the Research Experience for Undergraduates (REU) program, NSF's Research Experience for Teachers (RET) program allows currently funded investigators to add a supplement to their grant. Contact your NSF Program Director about this.

2. Contact colleagues in a nearby college of education and introduce yourself to the faculty who are engaged in SCIENCE EDUCATION. Find out what they are doing in the area of research or in PROFESSIONAL DEVELOPMENT for science teachers. See if they have a role for you in their activities. Such collaborations can be key elements in the Broader Impacts of your funded research.

3. Work with a science teacher or your college of education colleagues to develop a curriculum unit that involves the scientific inquiry you do in your laboratory (e.g., question development, data collection, analysis, problem solving). Volunteer to bring equipment necessary for the unit to the teacher's classroom during the lessons or design a low-tech version of the laboratory that can be enacted in the classroom. Many schools do not have fancy science laboratories and associated laboratory ware.

4. Following the suggestion above, along with your newfound colleagues in science education, help them design pro- 
fessional development projects or ways to offer your expertise in subject matter content via discussion-board interactions with teachers. The fact that you can (probably) answer their questions-in terms they can understand-will make you a treasured resource. You will learn better ways to talk about your science too. colleagues in the area where a meeting is to be held.

9. Go to your state's Department of Education Web site and drill down to your local school district. See who the Science Coordinator for the district is, and invite that person to your laboratory for a cup of coffee-show what you do and find out what he or she does. Look

\section{It is time for all of us to get more involved in...education.}

5. Take a teacher with you to your next scientific meeting and serve as tour guide, providing context and explaining why anyone should care about this or that particular presentation.

6. Give a teacher or a school library a subscription to a scientific journal.

7. As we enter the e-world of publishing, donate hard copies of journals to a high school library or to a county-level library that serves more than one school district (check first to see if they will accept them).

8. Attend a professional meeting that science educators attend: NSTA (National Science Teachers Association), AERA (American Educational Research Association), NMEA (National Marine Educators Association), NARST

(National Association of Research in Science Teaching), and others. Check out the organization on the Web first. Their programs and presentations are very relevant to how we teach science in higher education and communicate with the public about our science. They meet in some great locations, and maybe you can do double duty with visits to disciplinary for areas of overlap or common interest where you can help.

10. Talk to your children's teachersnot just about how your kids are doing (probably very well if they are in the type of nurturing home you doubtless provide), but about how you might help them do THEIR jobs. Remember, every teacher you help impacts up to 120 students with whom that teacher is in contact every week. The multiplier effect of helping teachers is truly amazing.

11. Volunteer to give a Career Day talk at a local school. It can be at ANY school, not just the one that your child attends. Judge the school's science fair. Do this on a regular basis.

12. Acquaint yourself with your state's science curriculum standards. They are available on the Web site of your state's Department of Education. They are listed by grade level and by subject area within grade level. You will be surprised what it is that teachers must address in their lesson plans. You might even find a few standards that are not quite what you might expect. If they need changing, learn how to get them changed! That in itself is quite an interesting lesson.

13. Learn how science teachers get certified to teach science in your state. There should be something about this on your state's Department of Education Web site. Contact preservice teaching program providers (e.g., Master of Arts in Teaching, MAT, or Master of Teaching, MT, degree programs) and see how you can help their efforts in putting well-qualified science teachers into our school systems. You might get asked to talk to aspiring science teachers about how science works for you!

14. Check out NSF's GK-12 program-it's awesome! Graduate students help science teachers in their schools as part of their graduate degree programs. Locate active programs in any state at this Web site: http://ehrweb. aaas.org/gk12new. NSF also has wellfunded programs for designing new curriculum (CCLI-Course, Curriculum, Laboratory Improvement) and that require collaboration between STEM and Education faculty (MSP-Math Science Partnerships).

15. While you are at it, check out the UTeach program at the University of Texas at Austin (http://uteach.utexas. edu) that is currently undergoing replication and expansion to other universities. This program has been successful in changing the way science is taught, and it involves professional scientists.

16. Many elementary and middle school science teachers also teach subjects in addition to science, for example, social science and literacy. Help them pick out an appropriate age-level science story to read, and design an activity to go along with the theme of the book. For example, it might be an ocean life story 
with an activity on food chains.

17. Many elementary school science teachers use kits to teach science. These kits are self-contained modules that come in boxes or plastic tubs about the size of a file cabinet drawer. Each is filled with materials, supplies, and items that are to be used in either demonstrations or hands-on activities. They come complete with lesson plans that address specific science content standards that can be taught as a curriculum unit. Teachers often don't fully understand the concepts incorporated or the context of the kit's lessons and have trouble making everyday connections for their students. Kit training is an essential element needed by elementary teachers, and that is where you might be able to help the most. Some kit activities will give you ideas about starting points for your own instruction. Check out these Web sites, for example, for FOSS, GEMS, and SEPUP kits:

- http://www.fossweb.com/searches/ freesearch.php;

- http://www.lhs.berkeley.edu/gems/ gemskits.html;

- http://www.lhs.berkeley.edu/sepup/ currmat.

18. Informal or "free choice" educational institutions-zoos, aquariums, botanical gardens, museums, nature centers-often need help with display materials and programs designed to inform the public. Teachers take classes on field trips to such places. If you are familiar with one, help a teacher design a lesson plan or develop a project that students can perform to illustrate what they learned on their visit. Or maybe you could accompany them on the trip and serve as a guide to the scientific content being displayed.
19. Any marine scientist would benefit from visiting a Centers for Ocean Science Education Excellence (COSEE) Web site (see http://www.cosee.net for a list) and then interacting with a coordinator who has direct links with science teachers. Their mission is to improve ocean science literacy by getting scientists and educators together, and there is a site near you.

20. Try to break the stereotype-not all scientists are white males with wild looking hair. If you are an under-represented minority in your field, you can make a huge difference simply by letting students know you are a scientist.

\section{SUMMARY}

What we are suggesting above is not rocket science. All kinds of research provide indicators about the best science teaching practices (think inquiry, as outlined in BIO 2010, 2003). We just need to act. All we are asking is that you help break the cycle of allowing science to be taught simply as factual information. Once teachers begin to really understand the process of scientific inquiry and the uncertainties that go along with it, they will become more effective at delivering science to their students. Remember, the science faculty at institutions of higher education are the scientific role models for virtually all elementary, middle, and high school science teachers.

We hope the list above will help you think of innovative and exciting ways to write and implement the Broader Impacts section required in grant proposals these days. Our only regret is that we don't know which of the above will have the greatest impact on learning for the largest number of students (and their teachers). This much we do know-we are fighting not just inad- equate science teaching, but also many other factors that work against having scientific literacy be known as cool these days (e.g., Staples, 2006; Bloom and Weisberg, 2007). Others among us are even calling for university presidents to get more involved in precollege education (Ryan, 2008). It is now time for YOU to get involved! 皿

\section{REFERENCES}

BIO 2010. 2003. Transforming Undergraduate Education for Future Research Biologists. National Academies Press, Washington, DC, 208 pp. Available online at http://www.nap.edu/ catalog.php?record_id=10497. Last accessed April 30, 2008.

Bloom, P., and D.S. Weisberg. 2007. Childhood origins of adult resistance to science. Science 316:996-997.

Chen, R.F. 2008. Ocean education and outreach for fame and fortune-A case study. Current, The Journal of Marine Education 24(1):36-40.

Feller, R.J. 2007. 110 Misconceptions about the ocean. Oceanography 20(4):170-173. Available online at http://www.tos.org/oceanography/issues/issue_ archive/20_4.html. Last accessed April 30, 2008.

Feller, R.J. 2008. An awakening (Part I). Oceanography 21(1):105-109.

Franks, S., J. McDonnell, C. Peach, E. Simms, and A. Thorrold. 2006. EPO, Education and Public Outreach, A Guide for Scientists. The Oceanography Society, Rockville, MD, 8 pp. Available online at: http://www.tos.org/epo_guide/index.html. Last accessed April 30, 2008.

Gallagher, R. 2007. Editorial. An iGEM of an idea: How to get students to go into science. The Scientist 20(12):13.

OECD 2006. Assessing scientific, reading, and mathematical literacy: A framework for PISA 2006 Programme for International Student Assessment. Pp. 19-42 (Chapter 1, Scientific Literacy) in Organisation for Economic Cooperation and Development. Available online at: http://www.oecd. org/dataoecd/63/35/37464175.pdf. Last accessed April 30, 2008.

Ryan, J.E. 2008. Say something! College presidents and public education. Education Week 27(20):36.

Staples, B. 2006. Why American college students hate science. New York Times, May 25, 2006. Available online at http://www.nytimes.com/2006/05/25/ opinion/25thu4.html. Last accessed April 30, 2008.

Spector, B.S., and C. Leard. 2008. Networks of Scientists and Educators: How to Make Them Work (draft). Available online at: http://www.barbaraspector. com/papers/networks.pdf. Last accessed April 30, 2008. 